\title{
Dinâmica populacional de Bemisia tabaci biótipo B (Gennadius, 1889) em cultivares de soja transgênica
}

\author{
Carlos Eduardo da Silva Oliveira ${ }^{1}$, Danilo Emanuel Flóride Carneiro ${ }^{1}$, Luciana Cláudia \\ Toscano $^{1}$, Renan Marcelo Ferreira dos Santos ${ }^{1}$ \\ ${ }^{1}$ Universidade Estadual de Mato Grosso do Sul, Unidade Universitária de Cassilândia, Cassilândia, Mato Grosso do Sul, Brasil. \\ E-mail: daniloemanuel@ hotmail.com, carllos_eduard@hotmail.com, toscano@uems.br, renanmarcelo_94@hotmail.com
}

Recebido: 11/01/2017; Aceito: 21/03/2018

\section{RESUMO}

A ocorrência de pragas é apontada como um dos principais fatores que causam perdas de produtividade na cultura da soja. A mosca-branca Bemisia tabaci biótipo B tem preocupado os sojicultores da região Centro-Oeste devido aos diversos danos causados. Com o uso cada vez maior de plantas com tecnologia $B t$ sendo implantadas nessas áreas, ainda são escassos estudos do impacto dessa tecnologia em pragas não-alvo. Objetivou-se, neste trabalho, avaliar a dinâmica populacional de $B$. tabaci biótipo $\mathrm{B}$, em diferentes cultivares de soja transgênica e relacioná-las com cultivares de soja convencional, verificando o impacto do uso da tecnologia $B t$ sobre a sua população. $\mathrm{O}$ experimento foi realizado em blocos ao acaso, com quatro tratamentos e cinco repetições. Os tratamentos foram constituídos pelas cultivares BRS 7980, NS 9280, NS 7000 IPRO e NS 7300 IPRO. A dinâmica populacional foi determinada através de amostragens semanais, realizando contagens diretas de ovos, ninfas e adultos de moscabranca em folíolos coletados e avaliados em laboratório. Não houve diferenças significativas entre as cultivares para números de ovos, ninfas e adultos em todas as avaliações devido à semelhança de pilosidade entre as cultivares. Concluiu-se que a cultivar NS 7000 foi a menos preferida para oviposição e a alimentação por Bemisia tabaci biótipo B é diretamente influenciada pela pilosidade das folhas na cultura da soja, ignorando a tecnologia presente na planta.

Palavras-chave: Mosca branca, amostragem, tecnologia Bt, Glycine max

\section{Population dynamics of Bemisia tabaci biotype B (Gennadius, 1889) in transgenic soybean cultivars}

\section{ABSTRACT}

The occurrence of pests is indicated as one of the main factors causing losses of production in the soybean crop. The silverleaf whitefly, Bemisia tabaci biotype B, has worried soybean farmers in the Central-West region of Brazil due to due to direct and indirect damage caused to plants. With the increasing use of $B t$-technology plants being deployed in these areas, there are still few studies of the impact of this technology on non-target pests. The objective of this study was to evaluate the population dynamics of B. tabaci biotype B in different cultivars of transgenic soybean and related them to conventional soybean cultivars, verifying the impact of $B t$ technology on its population. The experiment was in randomized blocks, with four treatments and five replicates. The treatments were composed of cultivars BRS 7980, NS 9280, NS 7000 IPRO and NS 7300 IPRO. Population dynamics were determined through weekly samplings, performing direct counts of eggs, nymphs and adults of silverleaf whitefly in leaflets collected and evaluated in the laboratory. There were no significant differences between cultivars for numbers of eggs, nymphs and adults in all evaluations. It was concluded that the NS 7000 cultivar was the least preferred for oviposition and feeding by $B$. tabaci biotype B is directly influenced by the hairiness of leaves in the soybean crop, ignoring technology present in the plant.

Key words: Silverleaf whitefly, sampling, $B t$ technology, Glycine max. 


\section{Introdução}

A soja [Glycine max L. Merrill] é uma oleaginosa de grande importância econômica para o setor agropecuário do Brasil. Na safra 2016/2017, a produção de grãos foi de 114 milhões de toneladas (CONAB, 2017).

A mosca-branca Bemisia tabaci (Gennadius, 1889) biótipo B (Hemiptera: Aleyrodidae) era considerada uma praga ocasional na cultura da soja no Brasil, entretanto, tornou-se a cada safra uma das principais causadoras de danos (LIMA; LARA, 2004), preocupando regiões produtoras como o Mato Grosso do Sul, a partir da safra 2012/2013 (DEGRANDE; VIVAN, 2013).

Segundo Silva et al. (2009), os danos da B. tabaci biótipo B podem ser diretos através da sucção da seiva da planta, tanto por ninfas, quanto por adultos ocasionando o depauperamento das plantas ou indiretos através da inserção de toxinas e introdução de vírus "necrose-da-haste" do grupo dos carlavirus. Sua excreção conhecida como honeydew é rica em açúcares servindo como ótimo substrato para o estabelecimento do fungo que causa a fumagina (Capnodium spp., Capnodiaceae) afetando principalmente a fotossíntese (LOPEZ et al., 2008).

A soja é uma das culturas de maior introdução de tecnologia para o controle de insetos, com o desenvolvimento de plantas geneticamente modificadas. As cultivares de sojas transgênicas que expressam as proteínas a partir de genes cry de Bacillus thuringiensis chamadas agronomicamente como soja $B t$, foram desenvolvidas para o controle de pragas da ordem Lepidoptera (YU et al., 2011). O que se tem observado nos últimos anos é um aumento do número de pragas não-alvo em áreas cultivadas com soja $B t$, isso em consequência, talvez, da diminuição das aplicações de inseticidas nas áreas que dispõem dessa tecnologia (OLIVEIRA et al., 2017).

No entanto, pouco se sabe sobre o impacto desta tecnologia na população dos insetos sugadores, e se em consequência disto obtivesse não preferência do inseto pelas plantas (OLIVEIRA et al., 2017). Desta forma, a busca por cultivares que sejam menos preferidas por Bemisia tabaci biótipo B, são de extrema importância. Sabendo que a antixenose ocorre quando um dado genótipo e/ou cultivar é menos utilizado ou preferido que outro em igualdade de condições, exercendo um efeito adverso no comportamento do inseto (BASTOS et al., 2015).

Assim, o objetivo do presente estudo foi avaliar a preferência por alimentação e, ou oviposição de $B$. tabaci biótipo B em diferentes cultivares de soja transgênica e convencional, além de verificar possíveis efeitos de antixenose nas plantas sob o ataque de moscabranca.

\section{Material e Métodos}

O estudo foi conduzido no campo experimental de Entomologia Agrícola da Universidade Estadual de Mato Grosso do Sul (UEMS), na Unidade Universitária de Cassilândia (UUC), em Cassilândia - MS (1905’ de latitude Sul e $51^{\circ} 48^{\prime}$ de longitude Oeste e $516 \mathrm{~m}$ de altitude) durante a safra 2015/2016.

$\mathrm{O}$ delineamento experimental utilizado foi blocos ao acaso, com quatro tratamentos e cinco repetições. Os tratamentos foram constituídos por quatro cultivares de soja BRS 7980 (convencional), NS 9280 (convencional), NS 7000 (transgênica) e NS 7300 (transgênica). A soja foi semeada no dia 03 de dezembro de 2015, em linhas espaçadas de $0,5 \mathrm{~m}$ e utilizando-se densidade de semeadura de 18 sementes por metro. Cada unidade experimental foi constituída por 6,0 $\mathrm{m}$ de comprimento e 2,5 $\mathrm{m}$ de largura (5 linhas de soja), totalizando $15 \mathrm{~m}^{2}$. As avaliações foram iniciadas aos 15 dias após a emergência das plantas (DAE), e, a partir desta data, foram realizadas a cada 7 dias, amostrando-se seis plantas da parcela útil - 3 linhas centrais (LIMA et al., 2002).

A dinâmica populacional da mosca-branca foi determinada através de amostragens semanais, de adultos, ovos e ninfas de B. tabaci biótipo B. Para contagem dos adultos utilizou-se a técnica da contagem direta de Moura et al. (2003), que consiste em contar os insetos presentes na face abaxial de um folíolo localizado no ápice de cada planta amostrada, no período entre 7:00 e 9:00 horas da manhã. Utilizou-se o auxílio de um espelho posicionado manualmente no inferior da folha de forma a não afugentar os adultos (BALDIN et al., 2005).

Para a amostragem de ovos e de ninfas de B. tabaci, biótipo B coletou-se um folíolo no segundo par de folhas a partir do ápice das plantas de cada uma das seis plantas amostradas (PEREIRA et. al., 2004). Estes folíolos foram colocados cuidadosamente em sacos plásticos transparentes, identificados e conduzidos ao laboratório de microscopia da UEMS/UUC, onde foram observados com o auxílio de estereoscópio com aumento de 40x e contado o número de ovos e ninfas na face abaxial dos folíolos.

Os dados foram agrupados mensalmente e submetidos à análise de variância e as médias comparadas ao teste de Tukey a 5\% de probabilidade. Para análise os dados foram transformados em $(\mathrm{x}+0,5)^{0,5}$.

\section{Resultados e Discussão}

Não foi observada a ocorrência de ovos, ninfas e adultos de $B$. tabaci biótipo B nas amostragens realizadas em dezembro no período em que os cultivares estavam no estágio fenológico V2. Suekane et al. (2013) 
não encontraram ninfas de $B$. tabaci biótipo $\mathrm{B}$ nas folhas de soja nos primeiros dias após a emergência devido à baixa população inicial de infestação, iniciando sua multiplicação nas cultivares.

Durante as avaliações de janeiro, fevereiro e março para contagem de ovos não se constatou diferenças significativas entre as cultivares convencionais e transgênicas; também não se verificou presença de ovos nas folhas da cultivar BRS 7980 no mês de janeiro, nas cultivares NS 9280, NS 7000 e NS7300 no mês de fevereiro e nas cultivares NS 7000 e NS 7300 no mês de março (Figura 1).

Conforme observado por Lima et al. (2002) não se verificou diferença significativa para o número médio de ovos no quadrante foliar aos 30 dias após emergência das plântulas de soja, o que pode ser justificado pela baixa população de Bemisia tabaci biótipo $\mathrm{B}$, apenas iniciando sua multiplicação nas cultivares (SUEKANE et al., 2013).
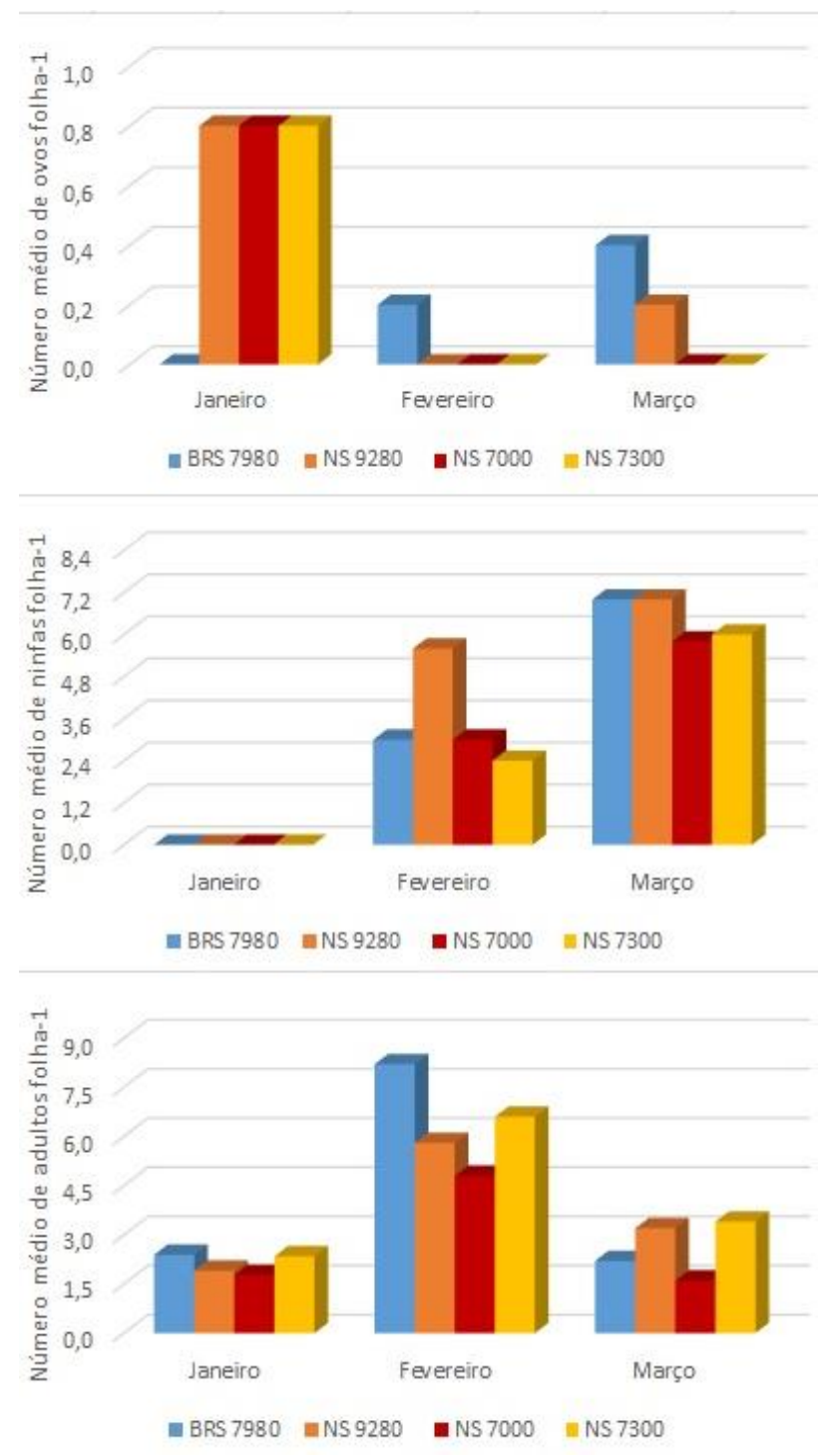

Figura 1. Número médio de ovos, ninfas e adultos de Bemisia tabaci biótipo B em quatro cultivares de soja durante os meses de janeiro, fevereiro e março de 2016. Cassilândia - MS. Safra 2015/2016.
A preferência de B. tabaci biótipo B pela planta pode estar relacionada com a pilosidade das folhas. Assim como Kahn et al. (2010) trabalhando somente com genótipos $B t$ verificaram certo grau de tolerância entre os genótipos de algodoeiros geneticamente modificados a Bemisia tabaci biótipo B. Se determinado genótipo apresenta características fisico-morfológicas que propiciam o aumento no comprimento dos tricomas presentes na folha, tal genótipo têm menor grau de tolerância ao inseto.

Sendo assim, independente da tecnologia presente na planta, se há semelhança entre a pilosidade das folhas estas serão mais preferidas para oviposição e/ou alimentação em relação às plantas com folhas de baixa pilosidade ou ausência de tricomas. Utilizando teste de preferência de oviposição com chance de escolha em 7 genótipos de soja, observa-se preferência da Bemisia tabaci biótipo B por folíolos com maior densidade de tricomas, ocorrendo maior número de ovos por $\mathrm{cm}^{2}$ (LIMA; LARA, 2004; VALLE; LOURENÇÃO 2002; ORIANI et al., 2008).

Tendo em vista que no presente trabalho a pilosidade dentro de um quadrante de $3,8 \mathrm{~cm}^{2}$ que foi mensurado em todo período experimental, verificando que a densidade dos tricomas variou em média de 160 para a cultivar BRS 7980 a 183,50 para a cultivar NS 9280 as demais cultivares ficaram dentro destas médias, demonstrando estra proximidade entre a pilosidade das cultivares.

Não houve ocorrência de ninfas no mês de janeiro em nenhuma das cultivares, porém, a partir do mês de fevereiro sua presença foi verificada; posteriormente no mês de março ocorreu o maior nível de sua infestação por folha, tendo em vista que sua população demanda tempo para completar seu ciclo biológico. A cultivar NS 7000 teve menor ocorrência de ninfas, apresentando menor número de ovos viáveis por folha no mês de março sendo a cultivar menos preferida para oviposição e/ou alimentação; o mesmo ocorreu para adultos nos meses de janeiro, fevereiro e março (Figura 1).

Suekane et al. (2013) não observaram diferenças significativas na incidência de mosca-branca entre as diferentes cultivares utilizadas, com e sem a tecnologia Bt. Os autores também observaram maior número de ninfas e adultos de B. tabaci biótipo B nos estádios de R1 e R2; resultados semelhantes ao presente estudo, no período de fevereiro a março, fato que pode se relacionar à pilosidade das folhas. Segundo Valle e Lourenção, (2002) genótipos de soja com maior pilosidade fornecem um microclima adequado para a oviposição das fêmeas de mosca-branca e maior proteção às ninfas.

As médias mensais de temperatura, umidade relativa do ar e precipitação pluvial foram coletadas e fornecidas para caracterização experimental (Figura 2). 


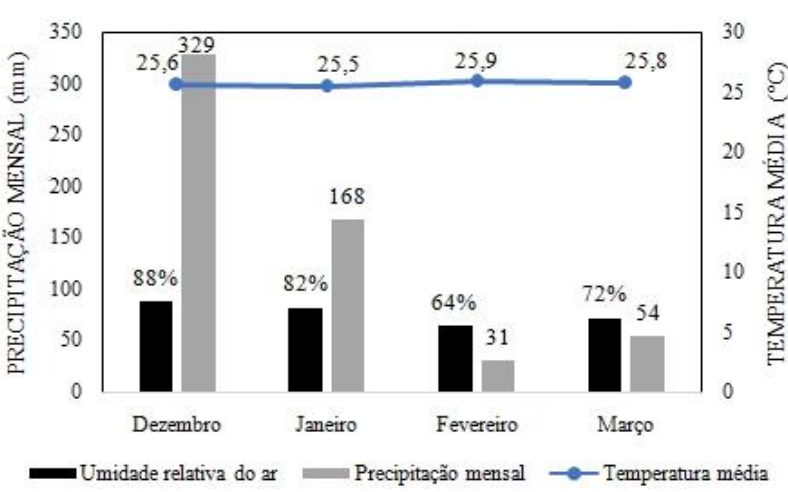

Figura 2: Precipitação pluvial (mm), umidade relativa do ar (\%) e temperatura média do ar $\left({ }^{\circ} \mathrm{C}\right)$ durante o período de amostragem da soja na safra 2015/2016, Cassilândia-MS.

Verificou-se um índice pluviométrico mais elevado na fase inicial das amostragens, fato que pode justificar a ausência de $B$. tabaci biótipo B no mês de dezembro e a baixa incidência no mês de janeiro. Como consequência observa-se queda no número de ovos e ninfas do inseto (Figura 2) visto que a precipitação pluviométrica exerce grande impacto nas populações da mosca-branca, existindo relatos de que períodos de precipitação intensa aumentam a mortalidade de ninfas (LIMA et al., 2011). A umidade relativa do ar e a temperatura também influenciam a dinâmica populacional de mosca-branca conforme Silva et al. (2014).

Jesus et al. (2010) relatam aumento no número de ninfas de B. tabaci biótipo B no fim de janeiro na safra das águas, o que é justificado pelo intenso volume de chuvas. Os autores ainda ressaltam que a maior incidência do inseto se deu a partir dos 60 dias após emergência, visto a necessidade do inseto de um longo período para se instalar e dar início ao ciclo biológico demonstrado nos meses seguintes.

\section{Conclusões}

Não houve impacto do uso da tecnologia $B t$ em cultivares de soja na dinâmica populacional de Bemisia tabaci biótipo B durante a safra 2015/2016.

A cultivar de soja NS 7000 foi a menos preferida para oviposição e alimentação por Bemisia tabaci biótipo B, devido ao efeito direto da presença de pilosidade das folhas.

\section{Agradecimentos \\ Ao Programa de Bolsa de Iniciação Científica "PIBIC/FUNDECT/CNPq/UEMS N 01/2015".}

\section{Referências Bibliográficas}

BALDIN, E. L. L.; VENDRAMIM, J. D.; LOURENÇÃO, A. L. Resistência de genótipos de tomateiro à mosca-branca
Bemisia tabaci (Gennadius) biótipo B (Hemiptera: Aleyrodidae). Neotropical Entomology, Londrina-PR, v. 34, n. 3, p. 435-441, 2005.

BASTOS, C. S. RIBEIRO, A. V.; SUINAGA, F. A.; BRITO, S. M.; OLIVEIRA, A. A. S.; BARBOSA, T. M.; SANTOS, P. de J.; OLIVEIRA, D. V. V.; TELCHMANN, Y. S. K. Resistência de plantas a insetos: contextualização e inserção no MIP. In: VISOTTO, L. E.; FERNADES, F. L.; CARVALHO FILHO, A.; LOPES, E. A.; AQUINO, L. A.; GOD, P. I. V. G.; RUAS, R. A. A.; SOUSA-JUNIOR, J. M. (Eds). Avanços tecnológicos aplicados à pesquisa na produção vegetal. Viçosa-MG: UFV, 2015. p. 32-72.

CAMPOS, Z. R.; BOIÇA JUNIOR, A. L.; LOURENÇÃO, A. L.; CAMPOS, A. R. Parâmetros biológicos de Bemisia tabaci (Genn.) biótipo B (Hemiptera: Aleyrodidae) em genótipos de algodoeiro. Bragantia, Campinas-SP, v. 68, n. 4, p. 10031007, 2009.

CONAB. COMPANHIA NACIONAL DE ABASTECIMENTO. SAFRA 2016/17- n. 12 - Décimo segundo levantamento. Brasília-DF: Conab: Brasília-DF, v. 4, n. 12, p. 1-158, 2017. Disponível em: <https://www.conab.gov.br/uploads/arquivos/16_12_08_09_2 6_15_boletim_graos_setembro_2017.pdf $>$. Acesso em: 27 abr. 2018.

DEGRANDE, P. E.; VIVAN, L. M. Tecnologia e Produção: Soja e Milho 2011/2012, Rondonópolis-MT: Fundação MT, p. $155-205,2012$.

HATCHETT, J. H.; BELAND G. L.; HARTWING, E. E. Leaf feeding resistance to bollworm and tobacco budworm in three soybean plant introductions. Crop Science, Madison, v. 16, n. 2, p. 277-280, 1976.

HARRISON, B. D. Advances in geminivirus research. Annual Review Phytopathology, Dundee, v. 23, n. 1, p. 5582, 1985.

JESUS, F.G.; BOIÇA JUNIOR, A. L.; CARBONELL, S. A. M.; STEIN, C. P.; PITTA R. M.; CHIORATO, A. F. Infestação de Bemisia tabaci biótipo B e Caliothrips phaseoli em genótipos de Feijoeiro. Bragantia, Campinas-SP, v. 69, n. 3 , p. 637-648, 2010

KHAN, M. A.; AKRAM W.; KHAN H. A. A.; ASGHAR J.; KHAN T. M. Impact of Bt- cotton on whitefly, Bemisia tabaci (Genn.) population. Pakistan Journal Agricultural Sciences, Faisalabad -PK v. 47, n. 4, p. 327-332, 2010.

LIMA, A. C. S.; LARA, F. M. Resistência de genótipos de soja à mosca-branca Bemisia tabaci (Genn.) biótipo B (Hemiptera: Aleyrodidae). Neotropical Entomology, Jaboticabal-SP, v. 33, n. 1, p. 71-75, 2004.

LIMA, A. C. S.; LARA, F. M.; BARBOSA, J. C. Preferência para oviposição de Bemisia tabaci (Genn.) biótipo B. (Hemiptera: Aleyrodidae) em genótipos de soja, sob condições de campo. Neotropical Entomology, Londrina- PR, v. 31, n. 2, p. 297-3003, 2002.

LIMA, J. S.; ASSUNÇÃO, I. P.; TEODORO, I.; LIMA, G. S.; MICHEREFF, S. J. Influência do sistema de irrigação na incidência e nas perdas ocasionadas pelo mosaico dourado do feijoeiro. Tropical Plantpathology, Brasília-DF, v. 36, n. 1, p. 50-53, 2011. 
LOPEZ V.; VOS, J.; POLAR, P.; KRAUSS, U. Discovery learning about sustainable management of whitefly pests and whitefly-borne viruses. International Centre for Tropical Agriculture (CIAT), Cali, Colômbia, v. 1, n. 1, p. 12-37, 2008.

LOURENÇÃO, A. L. F.; BARROS, R.; MELO, E. P. Milho Bt: uso correto da tecnologia. In: FUNDAÇÃO MS. Tecnologia e produção: Milho Safrinha e Culturas de Inverno 2010. Maracajú-MS: Fundação MS, 2009. p. 130.

MOURA, M. F.; PICANÇO, M. C.; SILVA, E. M.; GUEDES, R. N. C.; PEREIRA, J. L. Plano de amostragem do biótipo B de Bemisia tabaci na cultura do pepino. Pesquisa Agropecuária Brasileira, Brasília-DF, v. 38, n. 12, p. 1357$1363,2003$.

OLIVEIRA, C. E. S.; CARNEIRO, D. E. F.; TOSCANO, L. C.; FERREIRA, R. M. S.; ANDRADE, J. V. Preferência para oviposição de Bemisia tabaci (Gennadius 889) biótipo B em soja transgênica e não-transgênica. Tecnologia \& Ciência Agropecuária, João Pessoa-PB, v. 11, n. 6, p. 7-10, 2017.

ORIANI, M. A. G.; VENDRAMIM, J. D.; BRUNHEROTTO, R. T. Aspectos biológicos de Bemisia tabaci (Genn.) biótipo B (Hemiptera: Aleyrodidae) em seis genótipos de feijoeiro. Neotropical Entomology, Jaboticabal-SP, v. 37, n. 2, p. 191195, 2008.

PANIZZI, A. R; CÔRREA-FERREIRA, B. S. Dynamics in the insect fauna adaptation to soybean in the tropics. Trends in Entomology, Londrina-PR, v. 1, n. 1, p. 71-88, 1997.

PEREIRA, M. F. A.; BOIÇA JUNIOR, A. L., BARBOSA, J. C. Amostragem sequencial (presença-ausência) para Bemisia tabaci (Genn.) biótipo B (Hemiptera: Aleyrodidae) em feijoeiro (Phaseolusvulgaris L.) Neotropical Entomology, Jaboticabal-SP, v. 33, n. 4, p. 499-504, 2004.
RODRIGUES, T. R.; FERNANDES, M. G.; SANTOS, H. R. Distribuição espacial de Aphis gossypii (Glover) (Hemiptera, Aphididae) e Bemisia tabaci (Gennadius) biótipo B (Hemiptera, Aleyrodidae) em algodoeiro Bt e não-Bt. Revista Brasileira de Entomologia, São Paulo-SP, v. 54, n. 1, p. 136143, 2010.

SILVA, L. D.; OMOTO, C.; BLEICHER, E.; DOURADO, P. M. Monitoramento da suscetibilidade a inseticidas em populações de Bemisia tabaci (Gennadius) (Hemiptera: Aleyrodidae) no Brasil. Neotropical Entomology, PiracicabaSP, v. 38, n. 1, p. 116-125, 2009.

SILVA, A. G.; BOIÇA-JUNIOR, A. L.; FARIAS, P. R. S.; SOUZA B. H. S.; RODRIGUES N. E. L.; JESUS, F. G. Dinâmica populacional de mosca-branca Bemisia tabaci (Genn.) biótipo B (Hemiptera: Aleyrodidae) em feijoeiro. EntomoBrasilis, Vassouras-RJ, v. 7, n. 1, p. 05-11, 2014.

SUEKANE, R.; DEGRANDE, P. E.; LIMA JUNIOR, I. S.; QUEIROZ, M. V. B. M.; RIGONI, E. R. Danos da moscabranca Bemisia tabaci (Genn.) e distribuição vertical das ninfas em cultivares de soja em casa de vegetação. Arquivos Instituto Biológico. São Paulo-SP, v. 80, n. 2, p. 151-158, 2013.

VALLE, G. E.; LOURENÇÃO, A. L. Resistência de genótipos de soja a Bemisia tabaci (Genn.) biótipo B (Hemiptera: Aleyrodidae). Neotropical Entomology, Jaboticabal-SP, v. 31, n. 1, p. 285-295, 2002

YU H.L.; YUN, H. L.; HKONG, M. W. Risk assessment and ecological effects of transgenic Bacillus thuringiensis crops on non-target organisms. Journal Integrated de Plant Biology, Beijing, v. 53, n. 7, p. 520-538, 2011. 